\title{
La espiritualidad
}

ESTUDIOS_ ARTÍCULOS DE INVESTIGACIÓN

\section{de Pascal: los tres órdenes de realidad: cuerpo, espíritu,} caridad.

The spirituality of Pascal: the three orders

of reality: body, spirit, charity

Alicia Villar Ezcurra ${ }^{1}$

Universidad Pontificia Comillas, Madrid, España

Recibido 17 julio $2020 \cdot$ Aceptado 29 enero 2021

Resumen

Los escritos espirituales y los fragmentos dedicados a los tres órdenes de la realidad muestran que el pesimismo antropológico de Pascal no fue su última palabra. Es cierto que odia el endiosamiento del yo que hace que cada individuo se crea el centro de todo, y también que hay en él una llamada a la ascética y al desapego, propia de la espiritualidad de su tiempo que le aleja del lector contemporáneo. Sin embargo, en su espiritualidad cristocéntrica, con atisbos de misticismo, hay lugar para la esperanza y la alegría. Los fragmentos sobre los tres órdenes muestran el valor definitivo que asignó el orden de la caridad, subrayando el dinamismo espiritual de la afectividad, y apostando por el amor sin medida a lo eterno frente al sentimiento de trágica derrota.

Palabras clave: Blaise Pascal, espiritualidad, Tres órdenes, amor, caridad

\section{Abstract}

The spiritual writings and fragments dedicated to the three orders of the reality show that Pascal's anthropological pessimism was not his last thought. It is true that the deification of the self that makes each individual create himself the centre of everything is odious to him, and also that there is in him a call to asceticism and detachment, typical of the spirituality of his time that distances him from the contemporary reader. However, in his Christocentric spirituality, with hints of mysticism, there is room for hope and joy. The fragments on the three orders that will be analyzed here show the definitive value assigned by the order of charity, underlining the spiritual dynamism of affectivity, and betting on love without measure for the eternal against the feeling of tragic defeat.

Keywords: Blaise Pascal, spirituality, three orders, love, charity 


\title{
1・Introducción
}

\author{
Todo autor tiene un sentido con el cual todos los pasajes \\ contrarios concuerdan, o no tiene sentido alguno. No se puede \\ decir esto de la Escritura y de los profetas: tenían seguramente \\ demasiado buen sentido- Es menester, pues, buscar uno que \\ haga concordar todas las contradicciones. (L. 257)1
}

Este fragmento destaca la importancia de precisar las claves que dan sentido a los fragmentos más enigmáticos, pues como destaca L. Susini, el fruto antropológico de los Pensamientos parece haberse desprendido del árbol que los había producido². Para Pascal la ambivalencia, contradicción y paradoja del ser humano tienen una explicación en clave teológica que conviene explicitar para situar en su justa medida su visión trágica de la condición humana, cuyo pesimismo parece aproximarle a Hobbes ${ }^{3}$. Sus escritos espirituales explicitan su trasfondo teológico que se comprueba en numerosos fragmentos, especialmente los referidos a la segunda parte de su proyectada Apología de la religión cristiana ${ }^{4}$, así como en los dedicados a los tres órdenes de realidad que aquí analizaremos.

Sus reflexiones previas sobre la "miseria del hombre sin Dios" pueden parecer inclementes en tiempos de bienestar. Ciegos a la propia vanidad, las rutinas y los hábitos conforman una falsa seguridad que se quiebra cuando irrumpe lo terrible. Entonces la fragilidad e incertidumbre de la existencia se revela con toda su crudeza como consustancial a la vida humana. ¿Es este el mensaje definitivo de Pascal? ¿La condición humana

1 Seguimos la numeración de los fragmentos según la edición de Loius Lafuma que puede encontrarse en la edición de las Obras de Pascal de la editorial Gredos $(2012,2014)$. La traducción de los fragmentos es propia.

2 Cfr. L. Susini: Blaise Pascal, Spiritualité. Choix de Textes. Paris: Pocket. 2012, p. 9

3 Sainte Beuve relacionaba a Pascal con Hobbes, por su realismo pesimista (Sainte Beuve, III, 382-383). Cfr. J. Pucelle, "La politique de Pascal et la doctrine des trois ordres", en Chroniques de Port-Royal, no 10, 1951, p. 8-21

4 "(1) parte. Miseria del hombre sin Dios

(2) parte: Felicidad del hombre con Dios" (L.6, B. 60)

De los 1010 fragmentos de los Pensamientos aproximadamente 800 estarían destinados a la citada Apología. 
es ineludiblemente incierta y trágica? A nuestro juicio, el ordo amoris y los fragmentos sobre los tres órdenes resultan claves para descubrir el sentido al que alude el fragmento inicial, y permite situar en su justa medida su visión trágica de la existencia humana.

\section{2 - Duplicidad y ambivalencia de la condición humana}

Para el autor de los Pensamientos las contradicciones de la condición humana se comprueban en muy diversos planos y sus reflexiones parecen inspirarse tanto en sus experiencias del mundo social, como en las luchas libradas en su propio mundo interior. Con respecto al puesto que ocupa en el cosmos, la desproporción define al ser humano. Pascal percibe su pequeñez y grandeza según con quien se compare, pues "todo el mundo visible no es más que un trazo imperceptible en el amplio seno de la naturaleza" (L. 199). Si bien se espanta ante el silencio eterno de los espacios infinitos, también se asombra ante la inmensidad mucho menos visible que puede concebirse en el interior del más breve átomo. Precisamente, por no contemplar estos dos infinitos los hombres se lanzan con presunción a la búsqueda de los primeros principios para llegar a conocer el todo, como si tuvieran proporción con una naturaleza que les desborda. Así, inciertos y flotantes, como también observaba Montaigne, "ardemos en deseos de encontrar un asiento firme y una última base constante para edificar sobre ella una torre que se alce hasta el infinito", pero en realidad "todo nuestro fundamento cruje, y la tierra se abre hasta los abismos" (L. 199). Pascal explicará esta escisión en clave teológica, denunciando la ceguera de quien se considera el rey de la creación e ignora sus propios límites.

Actualizando temas que provienen de la Biblia, como la vanidad, la idolatría y el Dios oculto, en sus fragmentos describe las contradicciones del naciente mundo moderno, tanto en su dimensión social como individual. La vanidad y la superficialidad llevan a ocultar o desconocer la duplicidad del alma humana que Pascal extrema hasta la hipérbole. Al no poder remediar la muerte, la miseria y la ignorancia los hombres evitan pensar en ello y creen ser felices (L. 133). Con crudeza advierte Pascal que "corremos sin temor hacia el precipicio, después de haber puesto algo delante de 
nosotros que nos impide verlo" (L. 166). Así, los hombres se exponen a las más diversas agitaciones y peligros debido a que no saben permanecer en reposo en una habitación (L. 136), y huyen de la conciencia de su fragilidad y mortalidad con el ruido y el alboroto. Construyendo mecanismos de evasión, se busca la felicidad fuera de uno mismo, aturdidos y distraídos con el activismo, la diversión y el trato de nuestros semejantes, tan limitados e impotentes como nosotros (L. 144).

¿Es la soledad el remedio? Tampoco. Los filósofos estoicos recomiendan: recogeos en vuestro interior y encontraréis vuestro bien, pero lo que proponen en realidad es tan difícil como excepcional, observa Pascal (L. 144). En el propio interior no se encuentra la paz anhelada, pues la inestabilidad consustancial al alma humana propicia la inquietud. Por ello, el consuelo a nuestros males no se puede encontrar en nosotros mismos, ni tampoco en otros seres humanos, ni en nada de lo creado; sólo en Dios, dirá Pascal ${ }^{5}$. Ello se debe a que las criaturas no son la primera causa de lo que llamamos males, sino que debemos remontarnos a la Providencia de Dios para encontrar un alivio real.

\section{3-Ambivalencia humana y Teología agustiniana de la corrupción humana}

Si bien los fragmentos de los Pensamientos sobre la condición humana cobran actualidad en tiempos de crisis, su trasfondo teológico nos recuerda como todo autor se enraíza en el momento que le tocó vivir. Para Pascal toda la fe consiste en Adán y Jesucristo, un ser universal que ha permanecido desconocido entre los hombres y que los profetas anunciaron como un Dios oculto (L. 222 y L. 225).

El Dios de los cristianos es un Dios que hace sentir al alma que él es su único bien; que todo su reposo está en él, que solo tendrá alegría amándolo; y que le hace, al mismo tiempo, aborrecer los obstáculos que le retienen y le impiden amar a Dios con todas

5 "Carta del Sr. Pascal al Sr. Périer, su cuñado, con ocasión de la muerte del Sr. Pascal, su padre, 17 de octubre de 1651", en Blaise Pascal: Escritos espirituales, edición de Alicia Villar. Madrid: Tecnos. 2020, p. 13 
sus fuerzas. El amor propio y la concupiscencia, que la retienen, le son insoportables. Este Dios le hace sentir que tiene un fondo de amor propio que la pierde, y que solo él puede curarla. (L. 460)

La antropología y espiritualidad de Pascal van de la mano y muestra el propósito de su Apología: mostrar que la religión cristiana es digna de admiración, porque conoce bien al ser humano, y digna de ser amada porque promete el verdadero bien (L. 12). Nutrida de su interioridad y de su propia lectura de las Sagradas Escrituras, su espiritualidad refleja la huella de San Agustín y Jansenio ${ }^{6}$. Para San Agustín, y según el comienzo del Génesis y San Pablo, Dios creó al ser humano justo, santo, fuerte y sin concupiscencia y en ese estado de naturaleza inocente era plenamente feliz, abierto al amor infinito de Dios que colmaba la infinitud de su deseo. Pero Adán quiso afirmar su propia excelencia y constituirse en el centro de todo. Con ello introdujo el desorden y el ser humano quedó escindido perdiendo los privilegios que se le había concedido7. El hombre quiso concentrar su atención en sí mismo y prescindir de Dios; alejado de Él solo conservó una débil y confusa luz de su autor, y todas las criaturas o bien le afligen o le tientan y dominan (L. 149).

La razón de esta situación se detalla en la carta de Pascal a Étienne Périer escrita con motivo de la muerte de su padre (17 de octubre de 1651) ${ }^{8}$. Dios creó al hombre con dos amores: uno hacia Dios, un amor infinito, es decir sin ningún otro fin más que Dios mismo, el otro hacia sí mismo, un amor finito y referido a Dios. Al llegar el pecado se perdió el amor hacia Dios y el amor propio se desbordó, y así "se amó a sí solo y a todas las criaturas infinitamente". Pascal hace de estos dos amores dos principios y dos actitudes del corazón opuestas que se reparten la voluntad de los hombres. El pecado original, inicialmente incomprensible, le permite comprender la duplicidad actual del ser humano, y la religión cristiana ofrece el remedio: el orden del amor, el ordo amoris de San Agustín, establecerá una nueva unidad por medio del corazón, facultad de síntesis, que preside la jerarquía de

6 Ph. Sellier, "Pascal et Saint Augustin: Théologie et Anthropologie", en: PH. Sellier, Port-Royal et la literature, I. Pascal. Paris: Honoré Champion. 1999, p. 248

7 Cfr. Pascal: Textes choisis et présentés para Philippe Sellier. Paris: Points Essais, Editions du Seuil. 2009, p. 14

8 B. Pascal: Escritos espirituales, pp. 22-23 
los tres órdenes: corazón, espíritu, cuerpo, que veremos seguidamente.

\section{$4 \cdot$ Los tres órdenes de realidad}

La reflexión de Pascal sobre los distintos ordenes de realidad y de grandeza fue abordado desde distintas perspectivas y escritos. En los escritos conexos al Tratado del triángulo aritmético incluye una reflexión sobre distintos órdenes de grandeza que aplica al problema del cálculo de las áreas curvilíneas. Advierte que no se aumenta una grandeza continua cuando se añade, en tal número cualquiera, grandezas de un orden de infinitud inferior. Así, los puntos no añaden nada a las líneas, las líneas a las superficies, las superficies a los sólidos.

También se encuentra la reflexión sobre los órdenes referido a dignidades propias de la jerarquía social, y así aparece en la carta a la reina Cristina de Suecia en $1652^{10}$. Aquí solo distingue dos clases de órdenes el de los cuerpos y el de los espíritus, sin referirse al orden del corazón o de la caridad $^{11}$. Por último, en los Tres discursos sobre las condiciones de los grandes ${ }^{12}$ distingue dos clases de grandezas de distinto género y a las que debemos diferentes consideraciones: las institucionales, que dependen de la voluntad de los hombres, y las naturales, que son independientes de la imaginación porque consisten en cualidades reales y efectivas del alma o del cuerpo estimables por sí mismas. Ejemplos de las primeras son las dignidades y la nobleza; de las segundas las ciencias, la luz del espíritu, la virtud, la salud y la fuerza.

Nos centraremos en los fragmentos de los Pensamientos dedicados a

9 Cfr. P. Magnard, "Les trois ordres selon Pascal",en Revue de Métaphysique et de Morale, Janvier-Mars 1997, nº 1, p. 6. https://www.jstor.org/stable/40865913

10 En la sociedad del Antiguo Régimen se distinguen tres órdenes; la nobleza, el clero y el Tercer Estado. En este sentido orden significa un rango en el interior de una jerarquía. Cfr, Simone Manon. www/ philolog.fr/les trois ordres-pascal/

11 B. Pascal, "Carta a la Serenísima Reina de Suecia", en: Pensamientos. Las Provinciales, Opúsculos, Cartas, Obras matemáticas, Obras físicas, Estudio introductorio de Alicia Villar Ezcurra, Traducción de C. R. de Dampierre (Gredos, Biblioteca Grandes Pensadores, Madrid, 2012), p. 303

12 Existe una versión en español de estos Discursos en: B. Pascal: Pensamientos y otros escritos, Traducción de Eugenio d’Ors, México: Porrúa, pp. 410-414 
los tres órdenes, carne, espíritu o inteligencia, y caridad: los fragmentos L. 308 y L. 933, cuyo análisis revela una multitud de principios y aspectos implicados. Como advierte Julie Higaki, a modo de prisma, aparecen aspectos ontólogicos ${ }^{13}$, al considerar cuerpo, espíritu y caridad como categorías del ser, o clases de realidades; antropológicos, al entender que son elementos constitutivos del ser humano; y axiológicos pues cada uno de estos órdenes que persigue un objeto distinto tiene un determinado valor ${ }^{14}$. Además, el término "orden" puede significar ámbito de realidad, de sentido y valor, mientras que en otros fragmentos se refiere a método. Se comprueba ese sentido, cuando Pascal diferencia el orden del espíritu, del orden de la caridad. El primero procede por principio y demostración, el segundo consiste en la digresión sobre cada punto con relación al fin para mostrarlo siempre (L. 298), así el orden del corazón es la clave para interpretar fragmentos aparentemente inconexos.

El análisis del fragmento L. 308 sobre los tres órdenes, justifica su cita a pesar de su extensión:

La distancia infinita de los cuerpos con los espíritus ${ }^{15}$ representa la distancia infinitamente más infinita de los espíritus con la caridad, porque ella es sobrenatural.

Todo el brillo de las grandezas no tiene ningún lustre para la gente que se ocupa de las búsquedas del espíritu.

La grandeza de la gente de espíritu es invisible a los reyes, a los ricos, a los capitanes, a todos esos grandes de la carne.

La grandeza de la sabiduría, que es nula sino es de Dios, es invisible a los carnales y a la gente de espíritu. Son tres órdenes diferentes de género.

Los grandes genios tienen su imperio, su brillo, su grandeza, su victoria y su lustre y no tienen ninguna necesidad de grandezas carnales, con las que no tienen relación. Son vistos, no con los ojos, sino con el espíritu. Es suficiente.

Los santos tienen su imperio, su brillo, su victoria, su

13 Pascal se refiere a "tres órdenes de cosas".

14 J. Higaki, Péguy et Pascal: Les trois ordres et l'ordre du coeur, Presses Universitaires Blaise Pascal, Clérmont-Ferrand, 2005, cap. I

15 En el sentido de inteligencia. 
lustre y no tienen ninguna necesidad de grandezas carnales o espirituales, con las que no tienen relación alguna, porque ni añaden ni quitan. Son vistos por Dios y por los ángeles y no por cuerpos ni por espíritus curiosos. Dios les basta.

Arquímedes sin brillo sería objeto de la misma veneración. No ha librado sus batallas para los ojos, sino que ha alimentado a todos los espíritus con sus invenciones. ¡Cómo ha brillado entre los espíritus!

J.C. sin bienes, y sin ninguna aportación científica, está en su orden de santidad. No ha dejado invento alguno. No ha reinado en modo alguno, sino que ha sido humilde, paciente, santo, santo, santo para Dios, terrible para los demonios, sin pecado alguno. ¡Oh, con qué gran pompa ha venido y en una prodigiosa magnificencia ante los ojos del corazón que ven la sabiduría!

Hubiera sido inútil para Arquímedes hacer de príncipe en sus libros de geometría, aunque (él) lo fuese.

Le hubiera sido inútil a nuestro Señor J.C. venir como rey para brillar en su reino de santidad, pero vino adecuadamente con el brillo de su propio orden.

Es muy ridículo escandalizarse de la humildad de J.C., como si esa bajeza fuera del mismo orden que la grandeza que él venía a manifestar.

Que se considere aquella grandeza en su vida, en su pasión, en su oscuridad, en su muerte, en la elección de los suyos, en su abandono, en su secreta resurrección y en lo demás. Se verá que es tan grande que no habrá motivo para escandalizarse de una bajeza que no es tal.

Pero hay quienes no pueden admirar más que las grandezas carnales como si no las hubiera espirituales. Y otros que no admiran más que las espirituales como si no las hubiera infinitamente más elevadas en sabiduría.

Todos los cuerpos, el firmamento, las estrellas, la tierra y sus reinos, no valen lo que el menor de los espíritus. Porque él (espíritu) conoce todo esto y a sí mismo, y los cuerpos nada. 
Todos los cuerpos juntos y todos los espíritus juntos y todas sus producciones no valen lo que el menor movimiento de caridad. Eso es de un orden infinitamente más elevado.

De todos los cuerpos juntos no se podría obtener un pequeño pensamiento. Esto es imposible y de un orden distinto. De todos los cuerpos y espíritus no se podría extraer un impulso de verdadera caridad, es imposible y de otro orden, sobrenatural ${ }^{16}$.

El fragmento, sin apenas correcciones y de escritura cuidada, está casi terminado. Desde el punto de vista ontológico, cuerpo, espíritu y caridad son ámbitos de realidades, "cosas" de distinto género dirá Pascal en el fragmento L. $933^{17}$. Son realidades distintas como lo son el punto, la línea y la superficie, de ahí que sean inconmensurables.

Desde el punto de vista antropológico los tres órdenes expresan los modos de comprender el mundo a través de tres perspectivas distintas que corresponden a tres modos de ser. El fragmento no detalla tanto en que consiste el orden de los cuerpos, el orden del espíritu ${ }^{18} \mathrm{y}$ el orden de la caridad, sino que caracteriza a tres tipos humanos y tres tendencias presentes en cada uno de nosotros según las cuales se orienta la propia vida. ${ }^{19}$ La palabra "orden" comprende también la idea de una esfera de sentido como diría Paul Ricoeur ${ }^{20}$. Representa tres actitudes que definen por completo a un ser humano, posibilidades de existencia afines a los tres estadios de Kierkegaard: estético, ético y religioso. Se trata de un tipo de pertenencia a una esfera de sentido, que define al hombre de acción o al sabio ${ }^{21}$, en el caso de los dos primeros órdenes.

16 J. Mesnard, "Achèvement et inachèvement dans les Pensées de Pascal", en Studi francesi, 143, ano XLVIII, Maggio-agosto 2004, p. 311

17 En el fragmento 933 que se incluirá más adelante, Pascal se refiere a la carne, en vez de al cuerpo, y a la voluntad, en vez de a la caridad.

18 El término ésprit es polisémico en el francés del siglo XVII y en este fragmento tiene el sentido de inteligencia, a pesar de que mantengamos en el texto la traducción como "espíritu".

19 C. Letey: Apprendre a philosopher avec Pascal. Paris: Ellipses, 2012, pp. 62-78

20 P. Sécretain: Méditations kantiennes, en deça de Dieu, en dela de tout, L’Age d’Homme, Lausanne, 1981, p. 105

21 P. Sécretain, pp. 106 y ss 
Desde la perspectiva axiológica, los tres órdenes son objetos de diferente género para el alma, y las cosas se ordenan en tanto que objetos de la acción intencional del alma ${ }^{22}$. A la distancia infinita del espíritu con respecto al cuerpo, sucede la distancia "infinitamente infinita" de la caridad, con respecto al espíritu, pues lo perdurable no puede compararse con lo perecedero en su valor. Del orden del amor, sobre el que también hablará Max Scheler, emanan los sentimientos más profundos y la orientación última de la vida.

Hay distintos géneros de facultades según se refieran al cuerpo, al espíritu o inteligencia. Lo corporal remite a lo sensible, pero también al poder, a la fuerza o a la riqueza; el espíritu se refiere a la ciencia o al saber; el orden de la caridad al amor o a la voluntad como figura en el fragmento L. 933. A cada "orden de cosas" corresponde tres principios de conocimiento: sentidos, razón, fe ${ }^{23}$. Espíritu y corazón siguen órdenes distintos, métodos o procedimientos diferentes como nos señala el fragmento L. 298: "El corazón tiene su orden, el espíritu el suyo que es por principio y demostración. El corazón tiene otro. No se prueba que se debe ser amado exponiendo con el orden las causas del amor; eso sería ridículo". Cuerpo, espíritu y voluntad pueden ser orientados hacia Dios, definiendo tres modos de creer: costumbre, razón, inspiración (L. 808) ${ }^{24}$.

Los dos primeros órdenes, el de los cuerpos y el del espíritu son naturales, mientras que el orden de la caridad es sobrenatural, y es la gracia de Dios quien puede conducir a la santidad. Pascal no sólo clasifica la realidad según su cualidad, también según su cantidad como se mostrará por la significación del término "grandeza". Los carnales son los que tienen por objeto el cuerpo, ávidos de poder tanto de los seres como de las cosas. Representan al hombre que vive según el principio egocéntrico del mundo,

22 Cfr. M. Pécharman," L'ordre dans les trois ordres et l'ordre des trois ordres", en Révue de Métaphysique et de Morale, $\mathrm{n}^{0} 1$, 119, p. 23. https://www.jstor.org/stable/40865914

23 Para un desarrollo se este tema véase N. Degroote: L'ordre de l'ésprit. Paris: Le Cerf, 2016

24 La religión cristiana no admite como verdaderos hijos suyos a los que creen sin inspiración: "No es que excluya la razón y la costumbre, al contrario; pero hay que abrir el espíritu a las pruebas, confirmarse por la costumbre, y ofrecerse por medio de las humillaciones a las inspiraciones, las únicas que pueden hacer el verdadero y saludable efecto, ne evacuetur crux Christi" (L. 808) 
que se toma por su propio fin y que se vincula ciegamente a lo que es parcial y pasajero ${ }^{25}$. Dicho orden no es desdeñable por completo, pues de él se han derivado reglas admirables de policía, moral y justicia orientadas al orden público (L. 118, L. 210). Sin embargo, no hay que engañarse pues ofrecen una falsa imagen de la caridad, señala Pascal: el fondo villano, el figmentum malum, subsiste. Sólo está encubierto y no se ha suprimido (L. 211).

En cuanto a los espirituales representan a los sabios. El término espiritual, connota aquí inteligencia o racionalidad; de ahí que Arquímedes represente al sabio por excelencia. El espíritu se vincula con el pensamiento en el sentido cartesiano del término, y constituye la grandeza y dignidad del ser humano (L. 114), y es lo que lo distingue de los animales y de las máquinas: no es posible concebir a un hombre sin pensamiento, observa Pascal.

Alejandro, Arquímedes, Jesucristo, representan a tres figuras excelentes en los respectivos órdenes, carne, espíritu o inteligencia, caridad. Las palabras "distancia infinita" con las que se inicia el fragmento L. 308 resultan centrales, pues Pascal quiere subrayar la distancia inconmensurable entre los distintos órdenes, al ser de diferente género. Por ello las grandezas de un orden no representan nada para los que están en un orden distinto, "es invisible". Las grandezas de los bienes en el orden de los cuerpos, ejemplificado en los capitanes (fuerza), los ricos (las propiedades) o los reyes (poder), no tienen brillo para los que buscan la grandeza en el orden del espíritu. Estos aspiran al saber y al poder intelectual, y sus grandezas son invisibles para quienes se dejan dominar por el orden de los cuerpos; de forma parecida a como las grandezas del orden del espíritu son invisibles para ellos. Arquímedes, que representa la grandeza en el orden del espíritu, no libró las batallas para los ojos, sino que alimentó los espíritus con sus invenciones y brilló entre ellos. Mientras que ninguno de los órdenes inferiores puede comprender al orden superior, en cambio el superior puede juzgar a los inferiores. En los Tres Discursos sobre la condición de los Grandes, Pascal señala que "Dios está rodeado de gentes llenas de caridad que le piden los bienes de la caridad que están en su poder. Así él es propiamente el rey de la caridad" 26 . 
Se comprueba que no hay por parte de Pascal una negación del orden de los cuerpos, ni de los espíritus o inteligencias, sólo una advertencia de que su valor no es absoluto y que se corre el peligro de idolatrar lo que sólo tiene un valor relativo. El error, calificado por Pascal como tiranía o injusticia, consiste en hacer reconocer en un orden valores que solo pueden tenerlo en otro, queriendo por una vía lo que solo se puede obtener por otra (L. 58).

Confundir la esfera propia de cada orden conduce a la tiranía o al ridículo. El tirano es el que gobierna en un orden para el que no tiene ningún título legítimo, es decir trata de obtener por una vía lo que no puede obtener por la que le corresponde. Por ejemplo, quiere ser amado porque es fuerte, o bien obedecido porque es sabio, o temido porque es bueno, observa Comte Sponville $^{27}$. Tirano es el rey que quiere ser amado, el sabio que quiere reinar o el amante que quiere ser obedecido. El ridículo consiste en querer ser amado o temido en función de cualidades que no resultan pertinentes, pues para ser amado es preciso ser amable, al igual que para ser creído hay que ser creíble. La fuerza que merece creencia es el saber, y la confusión de un orden, o someter un orden dado a un orden inferior conduce a la barbarie ${ }^{28}$. Pierre Magnard señala que la teoría de los tres órdenes es el único antídoto a la tiranía, el único recurso capaz de mantener al ser humano de pie ${ }^{29}$.

\section{$5 \cdot$ Los tres órdenes y las tres concupiscencias}

Las observaciones de Pascal a propósito de los tres "órdenes de cosas" se vinculan con las tres concupiscencias en los citados fragmentos L. 933 y L. 545 que pertenecen a la serie de los "Papeles no clasificados" por Pascal.

Concupiscencia de la carne, concupiscencia de los ojos, orgullo, etc.

Hay tres órdenes de cosas. La carne, el espíritu, la

escritos, traducción de Eugenio Imaz. México: Porrúa. 1999, p. 414

27 A, Comte Sponville: Le capitalisme est-il moral? Paris: Albin Michel, 2009

28 Ibid.

29 P. Magnard: "Les trois "ordres" selon Pascal", p. 9 
voluntad.

Los carnales son los ricos, los reyes. Tienen por objeto el cuerpo.

Los curiosos y los doctos tienen por objeto el espíritu ${ }^{30}$.

Los sabios tienen por objeto la justicia.

Dios debe reinar sobre todo y todo referirse a él.

En las cosas de la carne reina propiamente la concupiscencia.

En los espirituales ${ }^{31}$, la curiosidad propiamente.

En la sabiduría, el orgullo propiamente.

No es que no podamos vanagloriarnos por el bien o

los conocimientos, pero no éste el lugar del orgullo, pues

concediendo a un hombre que es sabio no se dejará de

convencerle de que se confunde al ser soberbio.

El lugar propio de la soberbia es la sabiduría, porque no se puede conceder a un hombre que se ha vuelto sabio y que se confunde al vanagloriarse. Pues eso es de justicia.

Así sólo Dios concede la sabiduría, por lo cual: qui gloriatur in domino glorietur ${ }^{32}$.

Este fragmento L. 933 es considerado anterior al de los tres órdenes y lo prepara. Propone una clasificación que asigna a cada objeto su justo lugar y el orden al que pertenece ${ }^{33}$. Aquí también el término "espíritu", como en el fragmento L. 308 tiene el significado de inteligencia, y los "espirituales" representan a los doctos. En los dos fragmentos, L. 308 y L. 933, se alude a dos clases de sabiduría, una es divina y en ella reina la humildad y la caridad; la otra es humana y en ella reina el orgullo.34 Las tres concupiscencias son el efecto en las facultades humanas del amor de sí que impiden el amor a Dios. La fuente del desorden está en el orgullo humano y la idolatría que

30 En el sentido de inteligencia, dada la polisemia del término ésprit como se ha indicado anteriormente.

31 En el sentido de doctos.

32 Corintios, I, 31, "... el que se glorifica, glorifíese en el Señor"

33 Cfr. www/http/Penséesde pascal.fr

34 J. Higaki: "Pascal et Saint Paul", en Pascal, auteur spiritual. Textes réunis par Dominique Descotes. Paris: Honoré Champion, 2006, p. 77 
hace separarse del orden de Dios, accesible por medio del amor de Dios, revelado por Cristo..$^{35}$ Mientras que la cupiditas llama enemigo a lo que le aleja de sus fines temporales; la caridad, cuyo fin es el amor de Dios, considera enemigo a las concupiscencias que alejan de Dios. La oposición de la sabiduría que viene de Dios y la del mundo corresponde aquí a la oposición espiritual-carnal, fundamental para San Pablo y Pascal. Cristo es el hombre que tuvo más brillo y sin embargo gozó en su vida de menos brillo, muriendo traicionado y abandonado por todos ${ }^{36}$. El orgullo humano ciega la visión de la sabiduría divina que encierra la locura de la cruz. Los dos primeros órdenes se relacionan con dos concupiscencias (amor a las riquezas y al poder; curiosidad y orgullo en el caso del orden del espíritu); en cambio el orden de la caridad procede de la Gracia y la sabiduría evangélica. Como la fe, es un don de Dios sensible al corazón.

Los carnales siguen la concupiscencia de la carne; la concupiscencia de los ojos es la curiosidad, deseo de saber, y su nombre viene de la importancia que la vista tiene en el proceso del conocer. En cuanto al orgullo consiste en considerarse en creer que se puede ser bueno solo por el propio esfuerzo de la voluntad, como en el caso de los estoicos. En el fragmento L. 545 Pascal cita expresamente la concupiscencia de la carne o concupiscencia de los ojos y orgullo de la vida: Libido sentiendi, libido sciendi, libido dominandi ${ }^{37}$, y señala el medio para librarse del orgullo y mantenerse seguros y en paz. La firmeza de la fe proporciona un asiento firme, sin dejarse arrastrar por los ríos de fuego de las tres concupiscencias, como señala el

35 J. Higaki: "Pascal et Saint Paul", p. 78

36 L. 499 :"¿Qué hombre tuvo jamás más brillo?

El pueblo judío en su totalidad lo predijo antes de su venida. Los gentiles lo adoran después de su venida.

Esos dos pueblos, judío y gentil, lo miran como su centro.

Y sin embargo, ¿qué hombre gozó jamás menos de este brillo? De los 33 años, vivió 30 sin aparecer. Durante 3 años pasa por impostor. Los sacerdotes y los poderosos le rechazan. Sus amigos y sus más próximos le desprecian; finalmente, muere, traicionado por uno de los suyos, renegado por el otro y abandonado por todos.

¿Qué parte tiene él pues en este brillo? Jamás hombre alguno tuvo tanto brillo, jamás hombre alguno tuvo tanta ignominia. Todo este brillo sólo nos ha servido para hacérnoslo reconocible, pues él mismo no tuvo nada para sí".

37 I Jn, II, 16 
fragmento L. 545: "'Todo lo que existe en el mundo es concupiscencia de la carne, o concupiscencia de los ojos, u orgullo de la vida'38. Libido sentiendi, libido sciendi, libido dominandi ${ }^{39}$...”

Pascal aquí parece inspirarse en Juan (II, 16), frecuentemente retomado por San Agustín y sus discípulos, especialmente Jansenio. Jean Mesnard, Geneviéve Rodis-Lewis y Vincent Carraud precisaron las diferencias del análisis de Pascal con respecto a San Agustín y Jansenio. Jean Mesnard 40 recuerda que para San Agustín la primera concupiscencia se vincula al placer de los sentidos, en cambio para Pascal se vincula con la necesidad de poseer y dominar. En cuanto a la segunda concupiscencia consiste en una curiosidad frívola, mientras que para Pascal también se aprecia en la ciencia; por lo que se refiere a la tercera para los agustinianos se identifica con una voluntad de poder sobre los demás hombres que en Pascal se refiere más a la primera. Ello se comprueba en el fragmento L. 308 que considera grandes en el orden del cuerpo o de la carne a los capitanes, ricos y reyes, grandes en el orden de la carne. Es como si Pascal vinculara cada una de las concupiscencias con las cotas más altas que el hombre puede alcanzar en el plano meramente humano, propio del estado del hombre sin Dios. Geneviève Rodis-Lewis ${ }^{41}$ también destacó la reinterpretación de Pascal con respecto al pasaje del Nuevo Testamento (Juan II, 16), al referir la concupiscencia de la carne al anhelo de bienes materiales por parte de los reyes y los ricos; y la concupiscencia de los ojos a la libido sciendi, deseo de ser como un dios en el mundo y apropiarse del poder de juzgar sobre el bien y el mal42. Por último, Vicent Carraud destaca que Pascal tampoco sigue la doctrina jansenista de la delectación ${ }^{43}$. Recuerda que diversos editores de los Pensamientos observaron que la problemática de las tres concupiscencias le venía a Pascal

38 I Jn, I, 2,16

39 Nombre de las tres concupiscencias según San Agustín, voluptuosidad, curiosidad y orgullo

40 J. Mesnard: "Le thème des trois ordres dans l'organisation del Pensés", p. 30-36

41 G. Rodis-Lewis: "Les trois concupiscences", en Chroniques de Port-Royal, 1963, pp. 81-92

42 Cfr. M. Pécharman, "L'ordre dans les trois ordres et l'ordre des trois ordres", en Révue de Métaphysique et de Morale, $\mathrm{n}^{\circ} 2$, 1997, pp. 22-23

43 V. Carraud, "Des concupiscences aux ordres de choses", en Révue de Métaphysique et de Morale, $\mathrm{n}^{\circ} 1$ 1997, p. 41 
del Discours de la réformation de l'homme interieur44 de Jansenio, traducido por Arnauld d'Andilly. Sin embargo, Carraud observa que incluso aunque la redacción de Pascal está muy próxima a la de Arnauld d’Andilly su análisis es original. El orden de la carne no se refiere a los placeres de los sentidos, "la concupiscencia o el deseo de la carne", sino más bien del "amor al tener", observa Carraud 45 . Por ello, Pascal considera "grandes de la carne", a los reyes y ricos por excelencia, que se caracterizan por su necesidad de distinguirse, su orgullo y afán de poder.

Pascal asocia una concupiscencia a cada uno de los diferentes órdenes, que son ambivalentes, puesto que pueden seguir dos fines distintos: el mundo o Dios. ¿Es definitiva la escisión? El ordo amoris proporciona unidad de sentido de toda nuestra existencia, definida por el conjunto de valores escogido para vivir y orientar la propia existencia. El descenso a los infiernos que supone el enfrentarse a los abismos de la vanidad, orgullo y miseria, se purifica por la humildad, conciencia de la propia debilidad, y la apertura a un Dios que sostiene, ama y perdona. Mientras la conciencia de la miseria inculca desesperación y el orgullo presunción, la encarnación muestra la grandeza del remedio que ha sido necesario (L. 352). La esperanza alimenta la vida espiritual, esperando contra toda esperanza como San Pablo indica, el ordo amoris infunde confianza en el otro y en uno mismo.

\section{6 - Cristocentrismo, "ordo amoris" y caridad}

El ser humano es relación y necesita modelos que inspiren sus relaciones con los demás. Pascal no encuentra estos modelos a su alrededor ni tampoco en las distintas sectas filosóficas. En todas encuentra pegas: los escépticos al subrayar la miseria humana conducen a la desidia, y los estoicos al ensalzar la grandeza al orgullo y la prepotencia ${ }^{46}$.

Las tres concupiscencias se vinculan con las sectas filosóficas: "Las tres concupiscencias han hecho tres sectas y los filósofos no han hecho otra

44 V. Carraud, p. 45

45 Ibid., p. 50

46 Cfr. B. Pascal: La conversación con el Señor de Saci, Edición de Alicia Villar. Salamanca: Sígueme, 2005 
cosa que seguir una de las tres concupiscencias" (L. 145). Los carnales se representan en los epicúreos, los curiosos en los racionalistas y en los estoicos que sobrevaloran el dominio de la voluntad. Pero los estoicos se engañan al concluir que se puede siempre lo que algunas veces se puede (L. 146), de ahí que lo que proponen sea tan difícil como vano (L. 144). En definitiva, para Pascal las sectas filosóficas no pueden superar la limitación humana. Advierte: quien piensa que el ser humano puede ser perfectamente virtuoso por sí mismo y alcanzar por si solo directamente a Dios, ni conoce a Dios ni lo que es un hombre ${ }^{47}$. La conversión verdadera requiere anonadarse ante ese ser universal, y reconocer que sin Él no se puede nada (L. 378). Sin la conciencia de la propia miseria, que coexiste con el deseo de bien y verdad plena, el ser humano rinde culto a un yo imaginario que nos aparta del Dios, el Bien Supremo. Para Pascal Dios, que se oculta a sí mismo, solo puede conocerse por Jesucristo; sin ese mediador desaparece toda comunicación con Dios. Por Jesucristo y en Jesucristo se revela Dios y se enseña la moral, conociendo al reparador de nuestra miseria (L. 189).

Desde el punto de vista moral, para Pascal la diferencia del plano ético con el religioso-cristiano es clara. Su referente es Jesucristo, modelo de perfección y mediador del hombre con Dios, dos realidades inconmensurables. De él Isaías profetizó que podría su ley no en el exterior, sino en el corazón (L. 346). Pascal se admira de la sabiduría de los Evangelistas que presentan cualidades perfectamente heroicas en Jesucristo: capaz de temor y turbado cuando se turba él mismo, antes de morir, y después lleno de fuerza cuando los hombres le turban (L. 315). Ama a sus prójimos y su caridad se extiende hasta sus enemigos y los de Dios (L. 355).

En el fragmento 919, Misterio de Jesús, Pascal medita sobre la soledad de Cristo en Getsemaní y llama la atención la cercanía a su figura. Al final del fragmento siguen las palabras de Jesús en proximidad con quien reza, en relación personal y amistosa con el que le busca: “...Consuélate, no me buscarías sino me hubieses encontrado antes." "He pensado en ti durante mi agonía..." ${ }_{48}$. Siguiendo a Romano Guardini, impera un último misterio

47 Tercer Discurso, o.c., p. 414

48 Más adelante indica el fragmento: "Yo soy más tu amigo que tal o cual, puesto que he hecho más por ti que ellos, y ellos no padecerían por ti lo que yo he padecido y no morirían por ti". 
de amor y de unidad en las palabras de Jesús: "Te amo con mayor ardor con que tú has amado tu manchado ser". Así la fe aspira a la experiencia mística para convertirse en experiencia cotidiana y muestra la existencia cristiana, no como un sistema, sino como un encuentro resultado de la acción de Dios, en palabras de Guardini ${ }^{49}$.

Se explica así la auténtica sabiduría que ve los ojos del corazón, según el citado fragmento L. 308: "J.C. sin bienes, y sin ninguna aportación científica, está en su orden de santidad. El único objeto de la Escritura es la caridad y todo lo que no conduce a ella es figura" (L. 270). Cristo crucificado, según la primera Epístola de San Pablo a los Corintios, es un escándalo para los judíos y una locura para los gentiles, pero lo que parece una locura es más sabia que la sabiduría de todos los hombres, siempre que vean con los ojos del corazón.

El orden del amor, por mediación de Cristo, nos permite contrarrestar ese "yo odioso" ${ }_{50}$, ese amor propio desmedido que hace convertirse en Dios, en el centro de todo cuando no somos más que un punto, y que hace que los hombres se odien naturalmente uno al otro (L. 210). Así, la religión cristiana descubre las trampas de ese yo imaginario que se trata de embellecer ante los demás, y por medio de la humildad abre un nuevo orden abierto a la caridad. Jesucristo perdona lo que el ser humano no es capaz de perdonarse ni a sí mismo ni a los demás, ama a ese "yo" capaz de bien, y acoge y consuela al que sufre. Por su mediación, como en Kierkegaard, el ser humano ama al otro: uno se ama y ama porque es miembro de J.C: "se ama a J.C. porque él es el cuerpo del cual se es miembro. Todo es uno. Lo uno es en el otro, como las tres personas" (L. 372). En la comunidad con Cristo están contenidos todos los individuos como miembros de un cuerpo y la caridad recae sobre todos los hombres ${ }^{51}$.

Así se explica la alegría de los bienaventurados y de los cristianos, una alegría que el mundo no puede dar ni quitar según las palabras de San Juan y que no conoce la gente del mundo (XIV, 27, XVI, 22). A ella se refiere

49 R. Guardini, "La lucha de Pascal", en Blaise Pascal: Pensamientos y otros escritos, México: Editorial Porrúa, p. 22

50 "Haría falta que la verdadera religión enseñara la grandeza, la miseria, llevara a la estima y al desprecio de sí, al amor y al odio" (L. 450).

51 H. Arendt: El concepto de amor en San Agustín. Madrid: Encuentro, 2009, p. 142 
Pascal en su carta a Charlotte de Roannez de diciembre de 1656. Ahí observa que los bienaventurados tienen esa alegría sin ninguna tristeza y los cristianos tienen esa alegría mezclada con la tristeza por haber seguido otros placeres, y por el temor de perderla dado que esos placeres que tientan sin cesar. Por ello, hay que trabajar insistentemente en conservar esa alegría que modera nuestro temor, y a conservar ese temor que conserva nuestra alegría. Si nos libramos de la impiedad, la alegría será sin mezcla52.

\section{7· Consideraciones finales}

El fragmento L. 931 recoge un testimonio que parece corresponder a los propios sentimientos de Pascal y que inspiró la biografía de su hermana Gilberta:

Amo a todos los hombres como a mis hermanos porque todos están redimidos. Amo la pobreza, porque él la ha amado. Amo los bienes, porque me dan el medio de asistir a los miserables. Guardo fidelidad a todo el mundo. No devuelvo el mal a los que me lo hacen; sino que les deseo un estado parecido al mío, en la que no se recibe ni mal ni bien por parte de los hombres. Trato de ser justo, verdadero, sincero y fiel con todos los hombres ${ }^{53}$, y siento una ternura de corazón hacia los que Dios me ha unido más estrechamente.

Y esté yo sólo, o a la vista de los hombres, tengo en todas mis acciones presente la visión de Dios que debe juzgarlas y a quien las he consagrado todas.

Estos son mis sentimientos.

Y bendigo todos los días de mi vida a mi Redentor, que los ha puesto en mí, y que, de un hombre lleno de debilidades, de miseria, de concupiscencia, de orgullo y de ambición ha hecho

52 Blaise Pascal, Carta a Charlotte de Roannez, diciembre de 1658, en B. Pascal: Escritos espirituales, p. 123

53 Cfr. fragmento sobre la apuesta L. 418. "Ahora bien, ¿qué mal puede sucederos tomando este partido? Seréis fiel, honesto, humilde, reconocido, bienhechor, amigo sincero, verdadero...En verdad no estaréis infectados por el placer, la gloria, las delicias, pero ¿no tendreís otras cosas?" 


\section{un hombre exento de todos esos males por la fuerza de la gracia, a la cual toda la gloria es debida, no teniendo de mí más que la miseria y el error ${ }^{54}$.}

Ahora se comprende mejor la fuerza de la gracia y el trasfondo que permite decir a Pascal que nadie es más feliz que un auténtico cristiano, ni razonable, ni virtuoso, ni amable; en cambio con la honestidad, no se puede ser amable y feliz a la vez (L. 357 y L. 426). Como bien destacó Jean Mesnard, se comprueba la importancia de la teoría de los tres órdenes de Pascal. Más allá de su alcance cosmológico, matemático y metafísico, tiene un papel teológico central que caracteriza a una obra que revela tanto las alturas como los abismos ${ }^{55}$. Recapitulando, el orden de los cuerpos es contemplado como la extensión al modo de Descartes, por ello en el fragmento 308 Pascal califique como carnales a los reyes, ricos y capitanes, pues el cuerpo pueda ser objeto de conquista y dominio. El orden del espíritu corresponde a la inteligencia y la racionalidad, y su grandeza se ejemplifica en Arquímedes. Finalmente, el orden del amor revela el último sentido de las Escritura, restaura la escisión del ser humano y es el orden que siguió Jesucristo, San Pablo y San Agustín. Consiste "principalmente en la digresión sobre cada punto que tiene relación con el fin para mostrarlo siempre" (L. 298). Pascal refiere a Jesucristo, hijo de Dios vivo, el sentido inaugural de su advenimiento en la historia, como el centro al que todo tiende (L. 449).

A mi juicio, los fragmentos sobre los tres órdenes y los escritos espirituales de Pascal muestran que su pesimismo antropológico y moral no fue su última palabra. Sin duda, hay en él una llamada a la ascética y al desapego, propio de la espiritualidad de su tiempo; es cierto que sólo parece sensible a los aspectos oscuros de la existencia humana, lo que favoreció las críticas de los humanismos ateos al cristianismo; pero la lectura de un pensador torturado por su pesimismo sólo atendió a una parte de sus Pensamientos. En su espiritualidad cristocéntrica, con atisbos de misticismo, hay lugar para la esperanza y la alegría. En su dimensión escatológica, la caridad aparece como el principio y el fin de una historia orientada por el

54 Gilberta Pascal, en su Vida de Monsieur Pascal, se sirvió de esta nota autógrafa para organizar parte de su relato (\&51-70). (Cfr. P. Sellier: Pascal. Textes chosis. Editions Points, 2009, p. 213)

55 J. Mesnard, o.c., p. 17 
cristianismo y su espíritu, tal como aparece en el himno de la caridad de San Pablo. Y así Pascal destacó las contradicciones del ser humano, pero también subrayó el dinamismo espiritual de la afectividad, optando por el amor sin medida a lo eterno y la unión mística frente al sentimiento de trágica derrota.

\section{8 - Bibliografía}

Arendt, H. El concepto de amor en San Agustín. Madrid: Encuentro, 2009.

Carraud, V. "Des concupiscences aux ordres de choses", en Révue de Métaphysique et de Morale, $\mathrm{n}^{\mathrm{0}} 1,1997$.

Comte Sponville, A. Le capitalisme est-il moral? Paris: Albin Michel, 2009

Degroote, N. L'ordre de l'ésprit. Paris: Le Cerf, 2016.

Guardini, R. "La lucha de Pascal", en Blaise Pascal: Pensamientos y otros escritos, México: Editorial Porrúa.

Higaki, J. "Pascal et Saint Paul", en Pascal, auteur spiritual. Textes réunis par Dominique Descotes. Paris: Honoré Champion, 2006.

J. Higaki, Péguy et Pascal: Les trois ordres et l'ordre du coeur, Presses Universitaires Blaise Pascal, Clérmont-Ferrand, 2005.

Letey, C. Apprendre a philosopher avec Pascal. Paris: Ellipses, 2012, pp. 62-78. Magnard, P. "Les trois ordres selon Pascal", en Revue de Métaphysique et de Morale, Janvier-Mars 1997, $\mathrm{n}^{\mathrm{o}}$ 1. https://www.jstor.org/stable/40865913

Manon. Simone. www/ philolog.fr/les trois ordres-pascal/

Mesnard, J. "Achèvement et inachèvement dans les Pensées de Pascal", en Studi francesi, 143, ano XLVIII, Maggio-agosto 2004.

Pascal, B. "Carta a la Serenísima Reina de Suecia", en: Pensamientos. Las Provinciales, Opúsculos, Cartas, Obras matemáticas, Obras físicas, Estudio introductorio de Alicia Villar Ezcurra, Traducción de C. R. de Dampierre. Gredos, Biblioteca Grandes Pensadores, Madrid, 2012.

Pascal, B. "Tres discursos sobre la condición de grandes", en Pensamientos y otros escritos, traducción de Eugenio Imaz. México: Porrúa. 1999.

Pascal, B. Blaise Pascal: Escritos espirituales, edición de Alicia Villar. Madrid: Tecnos, 2020.

Pascal, B. La conversación con el Señor de Saci, Edición de Alicia Villar. Sala- 
manca: Sígueme, 2005.

Pascal, B. Pascal: Textes choisis et présentés para Philippe Sellier. Paris: Points Essais, Editions du Seuil, 2009.

Pascal, B. Pensamientos y otros escritos, Traducción de Eugenio d'Ors, México: Porrúa, año.

Pécharman, M. "L'ordre dans les trois ordres et l'ordre des trois ordres", en Révue de Métaphysique et de Morale, $\mathrm{n}^{\mathrm{0}}{ }_{1}, 119$. https://www.jstor.org/ stable/40865914

Pécharman, M. "L'ordre dans les trois ordres et l'ordre des trois ordres", en Révue de Métaphysique et de Morale, $\mathrm{n}^{0} 2,1997$.

Pucelle, J. "La politique de Pascal et la doctrine des trois ordres", en Chroniques de Port-Royal, $\mathrm{n}^{\mathrm{O}}$ 10, 1951, p. 8-21.

Rodis-Lewis, G. "Les trois concupiscences", en Chroniques de Port-Royal, 1963, pp. 81-92.

Sécretain, P. Méditations kantiennes, en deça de Dieu, en dela de tout, L'Age d'Homme, Lausanne, 1981.

Sellier, P. Pascal. Textes chosis. Editions Points, 2009.

Sellier, Ph. "Pascal et Saint Augustin: Théologie et Anthropologie", en: PH. Sellier, Port-Royal et la literature, I. Pascal. Paris: Honoré Champion,1999.

Susini, L. Blaise Pascal, Spiritualité. Choix de Textes. Paris: Pocket, 2012. 